\title{
Dynamics of Left Ventricular Ejection
}

\section{in Obstructive and Nonobstructive}

\section{Hypertrophic Cardiomyopathy}

\author{
Joseph P. Murgo, Barry R. Alter, James F. Dorethy, Stephen A. Altobelli, \\ and GEORGE M. MCGRAnahan, JR., with technical assistance by \\ Thomas E. Dunne, Cardiology Service, Department of Medicine, \\ Brooke Army Medical Center, Fort Sam Houston, Texas 78234
}

A B S T RACT The purpose of this study was to examine the dynamics of left ventricular ejection in patients with obstructive and nonobstructive hypertrophic cardiomyopathy (HCM). 30 patients with HCM and 29 patients with no evidence of cardiovascular disease were studied during cardiac catheterization. Using a single multisensor catheter, electromagnetically derived ascending aortic flow velocity and high fidelity left ventricular and aortic pressures were recorded during rest $(n=47)$ and provocative maneuvers $(n=23)$. Dynamic ventricular emptying during rest was also analyzed with frame-by-frame angiography $(n=46)$. Left ventricular outflow was independently derived from both flow velocity and angiographic techniques. The HCM patients were subdivided into three groups: (I) intraventricular gradients at rest $(n=9)$, (II) intraventricular gradients only with provocation $(n=12)$, and (III) no intraventricular gradients despite provocation $(n=9)$. During rest, the percentage of the total systolic ejection period during which forward aortic flow existed was as follows (mean \pm 1 SD): group I, $69 \pm 17 \%$ (flow), $64 \pm 6 \%$ (angio); group II, $63 \pm 14 \%$ (flow), $65 \pm 6 \%$ (angio); group III, $61 \pm 16 \%$ (flow), $62 \pm 4 \%$ (angio); control group, $90 \pm 5 \%$ (flow), $86 \pm 9 \%$ (angio). No significant difference was observed between any of the HCM subgroups, but compared with the control group, ejection was completed much earlier in systole independent of the

This paper was presented in part to the 50th Annual Scientific Sessions, American Heart Association, Miami, Fla., November 1977.

The opinions or assertions expressed herein are the private views of the authors and are not to be construed as reflecting the views of the Department of the Army of the Department of Defense.

Received for publication 6 April 1979 and in revised form 7 July 1980. presence or absence of intraventricular gradients. These results suggest that "outflow obstruction," as traditionally defined by the presence of an abnormal intraventricular pressure gradient and systolic anterior motion of the mitral valve, does not impede left ventricular outflow in HCM.

\section{INTRODUCTION}

Since Brock's first description two decades ago of an intraventricular systolic pressure gradient in three patients with "functional stenosis of the left ventricle" (1), the concept of a dynamic obstruction to left ventricular outflow has been the source of considerable research, discussion, and controversy. Some investigators have postulated a nonobstructive basis for the observed pressure gradients (2), whereas others believe obstruction to be incidental, with decreased diastolic compliance representing the major pathophysiologic problem (3). Despite these objections, a mechanical obstruction to left ventricular outflow remains the most widely accepted explanation for the abnormal hemodynamics and resulting clinical syndrome in hypertrophic cardiomyopathy with intraventricular pressure gradients $(4-11)$. The controversies in hypertrophic cardiomyopathy and the evidence both for and against the presence of obstruction have been recently reviewed by Criley et al. (12).

Implicit in the concept of obstruction is an understanding that outflow itself, i.e., ventricular ejection, is slowed, diminished, or impeded at some time during the systolic ejection period despite laboratory measurements that reveal rapid left ventricular emptying, high ejection fractions, and in most cases, a capability of virtually emptying the apical portion of the left ventricular cavity $(3,13,14)$.

Previous studies of the dynamics of ascending aortic flow in the presence of "outflow obstruction" have 
shown that almost all of the left ventricle's stroke volume is ejected in the first $50-60 \%$ of systole $(15,16)$. Pierce et al. (15) concluded that ejection was diminished in late systole because of a mechanical obstruction to left ventricular outflow, whereas Hernandez et al. (16) explained that the same phenomenon could have been secondary to a rapid and powerful ventricular contraction which resulted in an earlier completion of ejection. The former mechanism implies that left ventricular outflow is impeded during mid- and late systole, whereas the latter does not. To our knowledge, no previous studies of the dynamics of ascending aortic flow in nonobstructive hypertrophy cardiomyopathy have been reported. The purpose of this study was to analyze the patterns of left ventricular ejection in the presence and absence of intraventricular gradients to delineate further the relationship of obstruction to the dynamic pressure-flow characteristics in hypertrophic cardiomyopathy.

\section{METHODS}

\section{Patient population}

30 patients with hypertrophic cardiomyopathy scheduled to undergo elective cardiac catheterization formed the basis of this study. A control group was comprised of 29 patients catheterized for a variety of clinical indications, but in whom no evidence of cardiovascular disease was found. The study protocol was approved by the Clinical Investigation and Human Use Committees at Brooke Army Medical Center, and informed consent was obtained from all patients. Based on the results of catheterization, the patients with hypertrophic cardiomyopathy $(\mathrm{HCM})^{1}$ were subclassified into three groups: group I, the presence of abnormal resting intraventricular pressure gradients $(n=9)$; group II, the presence of

\footnotetext{
${ }^{1}$ Abbreviations used in this paper: ASH, asymmetric septal hypertrophy; HCM, hypertrophic cardiomyopathy; SEP, systolic ejection period; SV, stroke volume ejected; PVC, premature ventricular contraction.
}

intraventricular gradients only with provocative maneuvers ( $n=12$ ); and group III, the absence of intraventricular gradients despite provocative maneuvers $(n=9)$. The diagnosis of HCM was based on clinical and laboratory evaluation including echocardiographic findings of asymmetric septal hypertrophy (17) and/or typical findings on biplane left ventricular angiography (18). Symptoms were present in 27 of the $30 \mathrm{HCM}$ patients. Summaries of the patient population, study protocol and echocardiographic findings of the HCM patients are found in Tables I and II.

\section{Methods and equipment}

All cardiac medications had been discontinued a minimum of $72 \mathrm{~h}$ before catheterization. All patients were in a fasting state and either unsedated or lightly premedicated with Diazepam (10 mg per os Valium, Roche Laboratories, Nutley, N. J.). A left heart catheter containing two equisensitive solid state pressure sensors (Mikro-Tip, Millar Instruments, Inc., Houston, Tex.) was used in all 59 patients via a brachial arteriotomy approach. In 22 control subjects and $25 \mathrm{HCM}$ patients, a modification of this catheter contained an electromagnetic aortic flow velocity probe (Carolina Medical Electronics, Inc., King, N. C., 1973-1975; Millar Instruments, Inc., 1975-1978) located $9 \mathrm{~cm}$ from the tip or, in a later design, adjacent to the aortic pressure sensor (see Table I). The technical and calibration details of the solid state pressure sensors and the flow velocity probe have been presented elsewhere (19-26).

After the hemodynamic studies described below, the patients were allowed to return to a control state. The left heart multisensor catheter was replaced with either a United States Catheters and Instrumentation 8F National Institutes of Health angiography catheter or a Millar injection catheter (model PC-481, Millar Instruments, Inc.) with a pressure sensor mounted just above the injection ports. Biplane left ventricular cineangiograms at $60 \mathrm{frames} / \mathrm{s}$ were then performed while injecting $30-50 \mathrm{~cm}^{3}$ U. S. Pharmacopeia of diatrizoate maglumine and diatrizoate sodium injection (Renografin-76, E. R. Squibb and Sons, Inc., Princeton, N. J.) with the patient in the 30 degree right anterior oblique and 60 degree left anterior oblique projections. Standard quantitative angiographic calculations were performed from the right anterior oblique projection using the area-length method of Kasser and Kennedy (27). Coronary arteriography using the Sones technique was also performed in all control subjects and

TABLE I

Patient Population and Type of Studies Performed

\begin{tabular}{lccccc}
\hline & & \multicolumn{4}{c}{ Hypertrophic cardiomyopathy } \\
\cline { 3 - 6 } & Normal & Group I & Group II & Group III & All HCM \\
\hline Male patients & 23 & 5 & 9 & 6 & 20 \\
Female patients & 6 & 4 & 3 & 3 & 10 \\
Total & 29 & 9 & 12 & 9 & 30 \\
Age (mean \pm SD) $(y r)$ & $37 \pm 10$ & $37 \pm 17$ & $46 \pm 13$ & $42 \pm 13$ & $42 \pm 14$ \\
Rest study & 29 & 9 & 12 & 9 & 30 \\
Provocable study & 5 & $2 *$ & $12 \ddagger$ & $9 \S$ & 23 \\
Electromagnetic flow & 22 & 8 & 8 & 9 & 25 \\
Dynamic angiography & 22 & 6 & 10 & 8 & 24 \\
\hline
\end{tabular}

* One patient was given isoproterenol, one amyl nitrite.

$\$ 12$ patients were given isoproterenol.

$\S$ Eight patients were given isoproterenol, one amyl nitrite. 
TABLE II

Echocardiographic Data

\begin{tabular}{lcccc}
\hline & \multicolumn{4}{c}{ Hypertrophic cardiomyopathy } \\
\cline { 2 - 5 } & $\begin{array}{c}\text { Group } \\
\text { I }\end{array}$ & $\begin{array}{c}\text { Group } \\
\text { II }\end{array}$ & $\begin{array}{c}\text { Group } \\
\text { III }\end{array}$ & All HCM \\
\hline Number of subjects & 9 & 12 & 9 & $30(100 \%)$ \\
SAM & & & & \\
$\quad$ Present & 8 & 7 & 6 & $21(70 \%)$ \\
$\quad$ Severe & 5 & 1 & 1 & $7(33 \%)$ \\
$\quad$ Moderate & 3 & 3 & 1 & $7(33 \%)$ \\
$\quad$ Mild & 0 & 3 & 4 & $7(33 \%)$ \\
Absent & 0 & 3 & 3 & $6(20 \%)$ \\
$\quad$ Undefined & 1 & 2 & 0 & $3(10 \%)$ \\
Left ventricular & & & & \\
$\quad$ hypertrophy & & & & \\
ASH & 4 & 8 & 6 & $18(60 \%)$ \\
CH & 2 & 0 & 0 & $2(7 \%)$ \\
Other & $1^{*}$ & 1 & $2 *$ & $4(13 \%)$ \\
Undefined & 2 & 3 & 1 & $6(20 \%)$ \\
\hline
\end{tabular}

SAM, systolic anterior motion of mitral valve; ASH, asymmetric septal hypertrophy (septal/posterior wall ratio $>1.5$ ); $\mathrm{CH}$, concentric hypertrophy. Undefined, patients whose echocardiograms were technically inadequate for evaluation. * Septal/posterior wall ratios $>1.3$ but $<1.5$.

in all patients with HCM and chest pain ( 15 out of $30 \mathrm{HCM}$ patients). One patient in HCM group II was found to have insignificant coronary atherosclerosis.

\section{Study protocol}

All patients were studied in the supine position during the resting state. Patients with HCM who demonstrated no abnormal intraventricular gradients (or gradients $<20 \mathrm{~mm} \mathrm{Hg}$ ) were challenged with an isoproterenol infusion $(2-4 \mu \mathrm{g} / \mathrm{min})$ or amyl nitrite inhalation (see Table I). Five control subjects also underwent an isoproterenol infusion study. Cardiac outputs were measured at rest by the method of Fick and in 17 of the 25 patients challenged with isoproterenol. During each of these studies, the left heart catheter was manipulated so that simultaneous pressures were recorded from each of the following positions: $(a)$ tip sensor in the apical portion of the left ventricle and the second sensor ( $5 \mathrm{~cm}$ away) in the left ventricular outflow tract just below the aortic valve; (b) tip sensor in the left ventricle and the second sensor just above the aortic valve in the ascending aorta; $(c)$ tip sensor in the left ventricular outflow tract just below the aortic valve and the second sensor $5 \mathrm{~cm}$ away in the ascending aortic root. Standard hemodynamic and angiographic data are summarized in Table III.

\section{Data processing and analysis}

Flow velocity measurements and calculations. The ascending aortic flow velocity signal was replayed from analog tape and recorded simultaneously with left ventricular pressure, aortic pressure, electrocardiogram, and a respiratory signal on strip chart recordings at a minimum paper speed of $100 \mathrm{~mm} / \mathrm{s}$. A representative tracing taken from one of the normal control subjects is shown in Fig. 1. The spatial flow velocity profile in the ascending aortic root was assumed to be blunt $(28-30)$ and the flow velocity wave form representative of instantaneous volumetric flow. Each flow velocity signal was hand-digitized using an electronic digitizer coupled to a

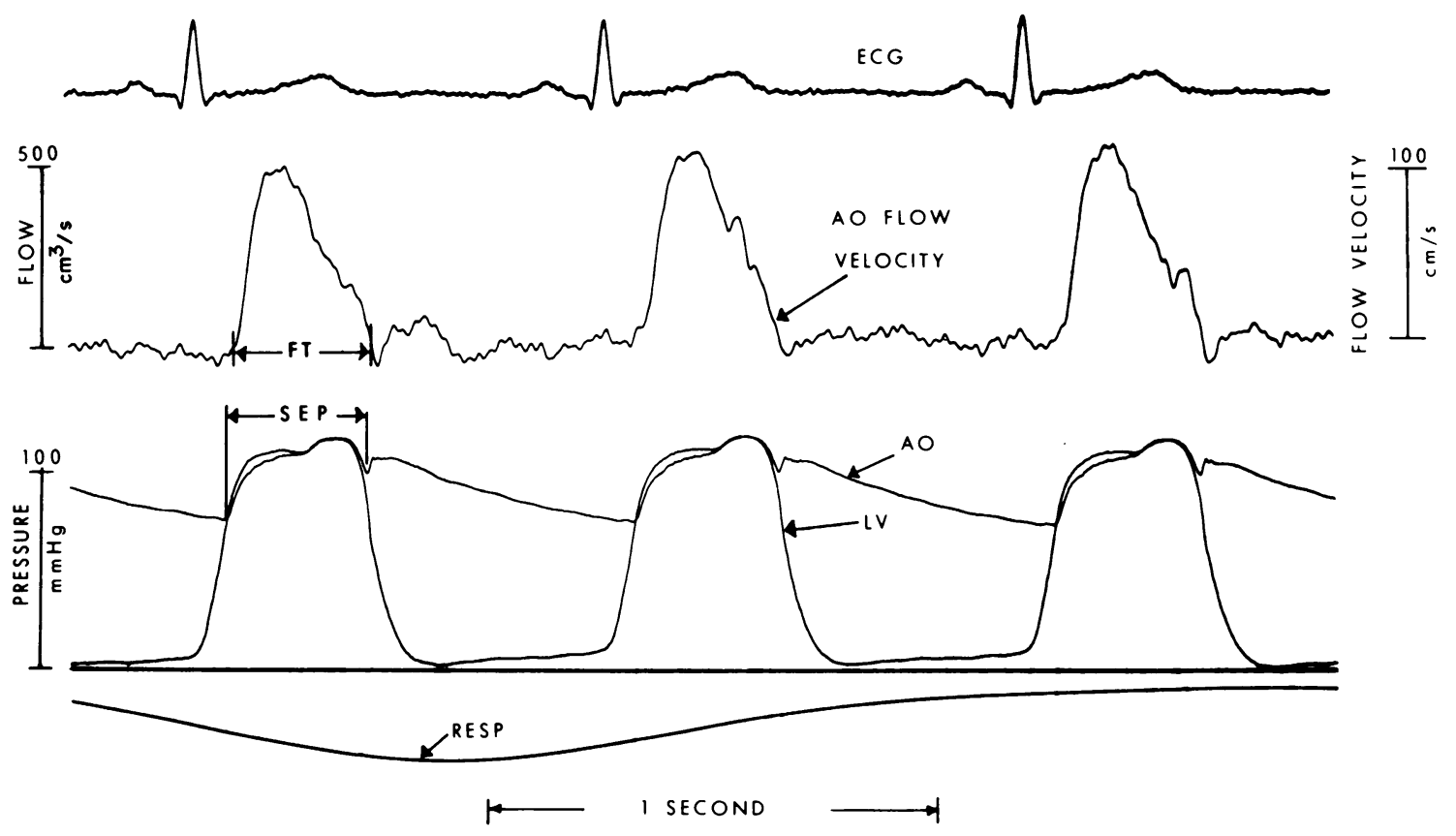

FIGURE 1 Multisensor catheter signals displayed with electrocardiogram (ECG) and respiration (RESP): AO, aorta; LV, left ventricle; FT, flow time, i.e., the duration of forward flow across the aortic valve. 
A. INDIVIDUAL FLOW SIGNALS

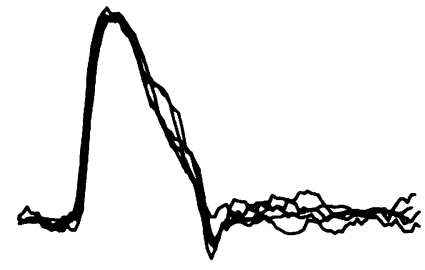

B. COMPUTER-AVERAGED FLOW SIGNAL

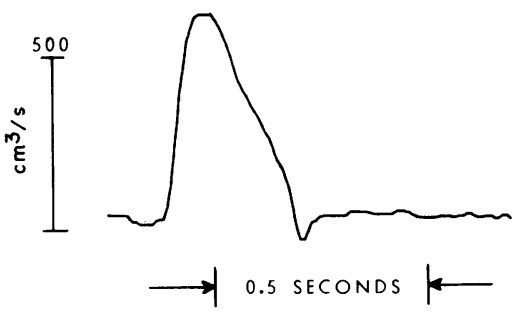

\section{TEMPORAL DISTRIBUTION OF EJECTION FROM AVERAGE FLOW SIGNAL}

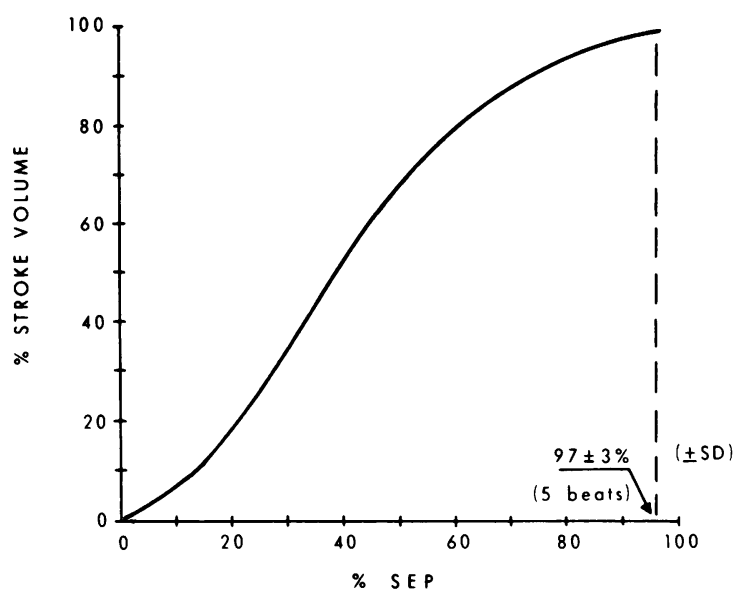

FIgURE 2 Panel A: sequential aortic flow velocity wave forms superimposed prior to computer integration. Panel B: computer-averaged flow velocity wave form scaled to volumetric flow using Fick cardiac outputs. Panel C: temporal distribution of left ventricular ejection in the normal control subject illustrated in Fig. 1. Ejection was completed in $97 \%$ of the SEP. This end-point value is equivalent to the ratio FT/SEP, where FT is defined in Fig. 1.

Hewlett-Packard 9830A programmable calculator (HewlettPackard Co., Palo Alto, Calif.) with a 2.5-million byte mass memory disc storage system. A minimum of two respiratory cycles were analyzed. Volumetric flow scales were established by setting the summated systolic areas under the flow velocity wave forms equal to the Fick-determined cardiac outputs scaled to the period of integration. The validity of using catheter-mounted electromagnetic flow velocity probes in studying ascending aortic flow in man has been previously reported by several other investigators $(25,31-36)$.

Each digitized flow wave form was stored and an average flow wave form computed and stored on an X-Y recorder (Fig. $2 \mathrm{a}$ and $2 \mathrm{~b})$. Peak systolic flow $\left(Q_{\mathrm{pk}}\right.$ in cubic centimeters per second) was determined from this average flow wave form. Flow data and derived indices are summarized in Table IV.

To analyze what percentage of the stroke volume was ejected at various times during systole, the average flow wave form was integrated, and the integral plotted against time as shown in Fig. 2c. To facilitate patient comparison during rest and inotropic stress with a wide range of heart rates, these data were normalized and plotted as the percent stroke volume ejected $(\% \mathrm{SV})$ against the percentage of the total systolic ejection period (\%SEP). The SEP was determined from the high fidelity central aortic pressure pulse, as shown in Fig. 1. Since the absolute duration of ejection (forward flow) is less than the SEP time interval, the latter will be referred to as the available SEP.

Angiographic techniques and analysis. Frame-by-frame analysis of the right anterior oblique left ventricular angiograms was performed using the same digitizer/calculator/ plotter system described above. A continuous-volume plot was generated from each angiogram with as many beats as was technically feasible. Only sinus beats were analyzed. Whenever possible, the sinus beat following a premature ventricular contraction (PVC) was avoided, but in 14 of 46 patients these were the only beats technically adequate for frame-byframe analysis. A single cycle is demonstrated before and after computer smoothing (two-pole, zero phase-shift, low-pass digital filter) (37) in Fig. 3a and 3b. The onset of forward flow was chosen from the angiographic frame in which the aortic valve was first seen to open (AVO in Fig. 3b). The point of aortic valve closure was identified from systolic ejection periods determined from a high fidelity aortic root pressure measured either simultaneously during the injection, or from previously measured beats at the same heart rate present during angiography, or from timing aortic valve closure from the cineangiogram itself. The temporal sequence of ventricular emptying was then displayed in a manner identical to that derived from the flow analysis by plotting the angiographically determined percent SV against the percent SEP. The angiographic percent SV at any point in systole was determined by the relationship:

$$
\% \mathrm{SV} \text { angio }=\frac{\mathrm{EDV}-\mathrm{V}(\mathrm{t})}{\mathrm{EDV}-\mathrm{ESV}} \cdot 100
$$

where EDV = end-diastolic volume, $\mathrm{ESV}$ = end-systolic volume, and $\mathrm{V}(\mathrm{t})=$ the ventricular volume at any point in systole as determined from the continuous volume curve in Fig. $3 \mathrm{~b}$.

Statistical analysis. All measured and derived data for each HCM subgroup were compared with the normal control population and each other using an analysis of variance with Scheffè's test for multiple comparisons (38). Whenever all HCM patients were compared with the control population as a single group, only an analysis of variance was employed.

\section{RESULTS}

\section{Standard laboratory data}

Echocardiographic findings. The pertinent echocardiographic findings for the patients with HCM are 
A. ANGIOGRAPHIC VOLUME CURVE

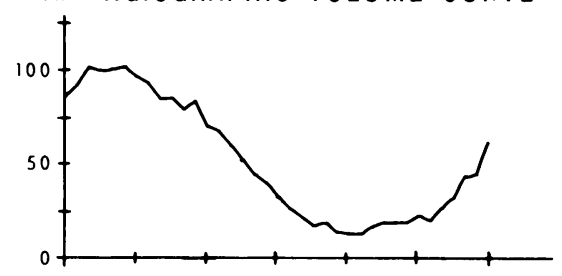

B. COMPUTER FILTERED VOLUME CURVE

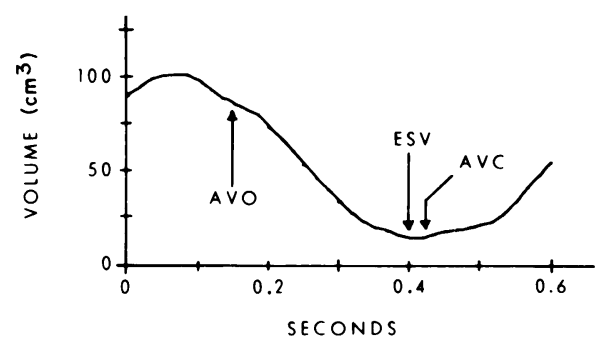

\section{TEMPORAL DISTRIBUTIOM OF EJECTION FROM ANGIOGRAPHIC VOLUME CURVE}

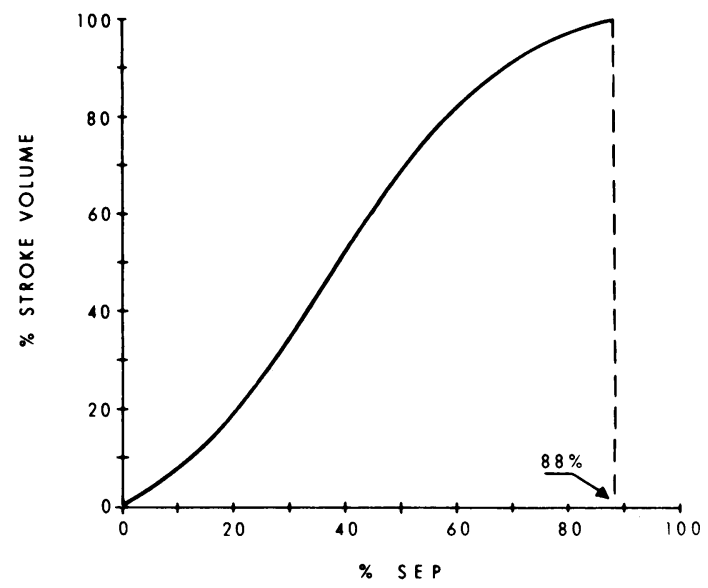

FigURE 3 Panel A: angiographically determined left ventricular volume plotted as a function of time. Panel B: same angiographic volume curve after computer processing. AVO, aortic valve opening; ESV, end-systolic volume; AVC, aortic valve closure. Panel C: temporal distribution of left ventricular ejection of another control subject demonstrating that ejection was completed in $88 \%$ of the SEP.

summarized in Table II. Asymmetric septal hypertrophy ( $\mathrm{ASH})$ (39) was present in all three $\mathrm{HCM}$ subgroups, with no significant difference in the degree of ASH between each of the subgroups. A higher prevalence and increased severity of systolic anterior motion of the mitral valve apparatus were present in group I patients, with lesser degrees of systolic anterior motion seen in groups II and III, respectively.

Hemodynamic findings. Resting heart rate, cardiac output, and stroke volume data were similar in the control group and all three HCM subgroups (Table III). Although only five control subjects were subjected to an isoproterenol infusion, changes in these parameters were all similar except for an average higher heart rate in the control group. The average resting intraventricular gradient (peak-to-peak) for group I was $51 \pm 23 \mathrm{~mm} \mathrm{Hg}$ during rest and $39 \pm 20 \mathrm{~mm} \mathrm{Hg}$ during exercise. Two patients demonstrated gradients of $<20 \mathrm{~mm} \mathrm{Hg}$, but these gradients were pansystolic and were not felt to be secondary to physiologic flow-generated gradients (23). These two patients were the only subjects of group I to undergo a provocative challenge. In group II, the average provoked gradient was $63 \pm 25 \mathrm{~mm} \mathrm{Hg}$. Left ventricular end-diastolic pressures were significantly elevated in all three HCM subgroups at rest. During isoproterenol infusion, left ventricular filling pressures tended to be abnormally high when compared with the control group, but because of the smaller sample sizes, statistically significant differences were not achieved.
There were no significant differences in the maximum rate of rise of left ventricular pressure (peak $d p / d t$ ) between any of the HCM groups and the normal control population.

Angiographic findings. Quantitative angiographic data are also summarized in Table III. Except for a tendency towards smaller end-diastolic volumes in HCM group II, this parameter was not significantly different when compared with the control population. However, end-systolic volume was significantly reduced in all three HCM subgroups. An interpretation of these results must include a realization of the limitations of applying mathematical models that assume the geometric shape of a prolate ellipse to ventricles that often have markedly distorted architecture, especially during end-systole. Significantly elevated ejection fractions were present in all the patients with HCM.

\section{Left ventricular outflow dynamics}

HCM group I: intraventricular gradients at rest. Fig. 4 illustrates the instantaneous pressure-flow relationships in a patient with a resting gradient, and is typical of the findings in all patients of group I. In panel A, the left heart catheter was placed so that both pressure sensors were within the left ventricle. An intraventricular gradient is displayed between the tip sensor in the apical portion of the left ventricle and the 
TABLE III

Standard Hemodynamic and Angiographic Data

\begin{tabular}{|c|c|c|c|c|c|c|c|c|c|}
\hline \multirow[b]{3}{*}{ Category } & & \multirow{3}{*}{$\frac{\text { Normal* }^{*}}{\text { Mean } \pm \text { SD }}$} & \multicolumn{7}{|c|}{ Hypertrophic cardiomyopathy } \\
\hline & & & \multicolumn{2}{|r|}{ Group I } & \multicolumn{2}{|r|}{ Group II } & \multicolumn{2}{|r|}{ Group III } & \multirow{2}{*}{$\frac{\text { All HCM }}{\text { Mean } \pm \text { SD }}$} \\
\hline & & & $n$ & Mean \pm SD & $n$ & Mean \pm SD & $n$ & Mean \pm SD & \\
\hline BSA & & $1.94 \pm 0.20$ & 9 & $1.81 \pm 0.32$ & 12 & $1.90 \pm 0.21$ & 9 & $1.94 \pm 0.23$ & $1.89 \pm 0.25$ \\
\hline Heart rate $(B P M)$ & $\begin{array}{l}\mathrm{R} \\
\mathrm{P}\end{array}$ & $\begin{array}{r}77 \pm 12 \\
140 \pm 19\end{array}$ & $\begin{array}{l}9 \\
2\end{array}$ & $\begin{array}{l}76 \pm 19 \\
95 \pm 6\end{array}$ & $\begin{array}{l}12 \\
12\end{array}$ & $\begin{array}{r}76 \pm 13 \\
120 \pm 15\end{array}$ & $\begin{array}{l}9 \\
8\end{array}$ & $\begin{array}{c}71 \pm 6 \\
114 \pm 9 \S\end{array}$ & $\begin{array}{c}74 \pm 13 \\
115 \pm 14 \S\end{array}$ \\
\hline $\begin{array}{l}\text { Cardiac index } \\
\quad\left(\text { liters } / \mathrm{min} / \mathrm{m}^{2}\right)\end{array}$ & $\begin{array}{l}\mathbf{R} \\
\mathbf{P}\end{array}$ & $\begin{array}{l}3.5 \pm 0.4 \\
6.1 \pm 1.2\end{array}$ & $\begin{array}{l}9 \\
1\end{array}$ & $\begin{array}{l}3.4 \pm 0.5 \\
6.8 \pm 0\end{array}$ & $\begin{array}{r}12 \\
7\end{array}$ & $\begin{array}{l}3.5 \pm 0.7 \\
5.6 \pm 1.8\end{array}$ & $\begin{array}{l}9 \\
5\end{array}$ & $\begin{array}{l}3.7 \pm 0.9 \\
7.0 \pm 1.4\end{array}$ & $\begin{array}{l}3.5 \pm 0.7 \\
6.2 \pm 1.6\end{array}$ \\
\hline Stroke index $\left(\mathrm{cm}^{3} / \mathrm{m}^{2}\right)$ & $\begin{array}{l}\mathbf{R} \\
\mathbf{P}\end{array}$ & $\begin{array}{l}46 \pm 7 \\
47 \pm 9\end{array}$ & $\begin{array}{l}9 \\
1\end{array}$ & $\begin{array}{l}46 \pm 9 \\
75 \pm 0\end{array}$ & $\begin{array}{r}12 \\
7\end{array}$ & $\begin{array}{l}47 \pm 13 \\
48 \pm 19\end{array}$ & $\begin{array}{l}9 \\
5\end{array}$ & $\begin{array}{l}53 \pm 13 \\
58 \pm 9\end{array}$ & $\begin{array}{l}48 \pm 12 \\
54 \pm 17\end{array}$ \\
\hline $\begin{array}{l}\text { Pulmonary capillary pres- } \\
\text { sure mean }(\mathrm{mm} \mathrm{Hg})\end{array}$ & $\begin{array}{l}\mathbf{R} \\
\mathbf{P}\end{array}$ & $\begin{array}{l}7 \pm 2 \\
2 \pm 1\end{array}$ & $\begin{array}{l}9 \\
1\end{array}$ & $\begin{array}{l}13 \pm 4^{\prime \prime} \\
11 \pm 0\end{array}$ & $\begin{array}{r}11 \\
6\end{array}$ & $\begin{array}{l}9 \pm 4 \\
8 \pm 4\end{array}$ & $\begin{array}{l}9 \\
4\end{array}$ & $\begin{array}{r}10 \pm 3 \\
8 \pm 2\end{array}$ & $\begin{array}{c}11 \pm 4 \S \\
8 \pm 3\end{array}$ \\
\hline $\begin{array}{l}\text { Left ventricle systolic } \\
\qquad(m m \mathrm{Hg})\end{array}$ & $\begin{array}{l}\mathbf{R} \\
\mathbf{P}\end{array}$ & $\begin{array}{l}117 \pm 11 \\
128 \pm 17\end{array}$ & $\begin{array}{l}9 \\
2\end{array}$ & $\begin{array}{l}155 \pm 33^{\prime \prime} \\
145 \pm 31\end{array}$ & $\begin{array}{l}12 \\
12\end{array}$ & $\begin{array}{l}136 \pm 18 \\
178 \pm 28 \S\end{array}$ & $\begin{array}{l}9 \\
9\end{array}$ & $\begin{array}{l}131 \pm 32 \\
125 \pm 25\end{array}$ & $\begin{array}{l}140 \pm 28 \S \\
154 \pm 36\end{array}$ \\
\hline $\begin{array}{l}\text { Left ventricle diastolic } \\
\qquad(m m H g)\end{array}$ & $\begin{array}{l}\mathbf{R} \\
\mathbf{P}\end{array}$ & $\begin{array}{l}9 \pm 3 \\
5 \pm 2\end{array}$ & $\begin{array}{l}9 \\
2\end{array}$ & $\begin{array}{l}16 \pm 5 \\
10 \pm 0\end{array}$ & $\begin{array}{l}12 \\
12\end{array}$ & $\begin{array}{l}13 \pm 6 \S \\
14 \pm 8\end{array}$ & $\begin{array}{l}9 \\
9\end{array}$ & $\begin{array}{c}15 \pm 5 \\
9 \pm 5\end{array}$ & $\begin{array}{l}15 \pm 5 \S \\
12 \pm 7\end{array}$ \\
\hline Peak $d p / d t(m m H g / s)$ & $\begin{array}{l}\mathbf{R} \\
\mathbf{P}\end{array}$ & $\begin{array}{l}1,576 \pm 299 \\
4,560 \pm 1,119\end{array}$ & $\begin{array}{l}9 \\
2\end{array}$ & $\begin{array}{l}1,667 \pm 591 \\
2,488 \pm 301\end{array}$ & $\begin{array}{l}12 \\
12\end{array}$ & $\begin{array}{l}1,781 \pm 223 \\
4,348 \pm 658\end{array}$ & $\begin{array}{l}9 \\
9\end{array}$ & $\begin{array}{l}1,782 \pm 396 \\
3,647 \pm 1,403\end{array}$ & $\begin{array}{l}1,746 \pm 402 \\
3,924 \pm 1,102\end{array}$ \\
\hline Aortic systolic $(m m \mathrm{Hg})$ & $\begin{array}{l}\mathrm{R} \\
\mathrm{P}\end{array}$ & $\begin{array}{l}116 \pm 11 \\
117 \pm 16\end{array}$ & $\begin{array}{l}9 \\
2\end{array}$ & $\begin{array}{r}104 \pm 15 \\
92 \pm 26\end{array}$ & $\begin{array}{l}12 \\
12\end{array}$ & $\begin{array}{l}136 \pm 18 \S \\
116 \pm 16\end{array}$ & $\begin{array}{l}9 \\
9\end{array}$ & $\begin{array}{l}131 \pm 32 \\
126 \pm 29\end{array}$ & $\begin{array}{l}125 \pm 26 \\
117 \pm 23\end{array}$ \\
\hline Aortic diastolic $(\mathrm{mm} \mathrm{Hg})$ & $\begin{array}{l}\mathbf{R} \\
\mathbf{P}\end{array}$ & $\begin{array}{l}76 \pm 7 \\
77 \pm 9\end{array}$ & $\begin{array}{l}9 \\
2\end{array}$ & $\begin{array}{l}66 \pm 7 \\
60 \pm 15\end{array}$ & $\begin{array}{l}12 \\
12\end{array}$ & $\begin{array}{l}82 \pm 13 \\
72 \pm 12\end{array}$ & $\begin{array}{l}9 \\
9\end{array}$ & $\begin{array}{l}80 \pm 13 \\
66 \pm 17\end{array}$ & $\begin{array}{l}77 \pm 13 \\
69 \pm 14\end{array}$ \\
\hline Aortic mean $(\mathrm{mm} \mathrm{Hg})$ & $\begin{array}{l}\mathbf{R} \\
\mathbf{P}\end{array}$ & $\begin{array}{l}95 \pm 9 \\
92 \pm 13\end{array}$ & $\begin{array}{l}9 \\
2\end{array}$ & $\begin{array}{l}85 \pm 7 \\
71 \pm 6\end{array}$ & $\begin{array}{l}12 \\
12\end{array}$ & $\begin{array}{r}104 \pm 14 \\
87 \pm 14\end{array}$ & $\begin{array}{l}9 \\
9\end{array}$ & $\begin{array}{r}106 \pm 19 \\
89 \pm 24\end{array}$ & $\begin{array}{l}99 \pm 16 \\
86 \pm 18\end{array}$ \\
\hline $\begin{array}{l}\text { Peak-to-peak gradient } \\
\quad(\mathrm{mm} \mathrm{Hg})\end{array}$ & $\begin{array}{l}\mathrm{R} \\
\mathrm{P}\end{array}$ & - & $\begin{array}{l}9 \\
2\end{array}$ & $\begin{array}{l}51 \pm 23^{\prime \prime} \\
54 \pm 5^{\prime \prime}\end{array}$ & $\begin{array}{l}12 \\
12\end{array}$ & - & $\begin{array}{l}9 \\
9\end{array}$ & - & $\begin{array}{l}\text { NC } \\
\text { NC }\end{array}$ \\
\hline $\begin{array}{l}\text { End diastolic volume } \\
\text { index }\left(\mathrm{cm}^{3} / \mathrm{m}^{2}\right)\end{array}$ & & $69 \pm 17$ & 6 & $71 \pm 15$ & 10 & $53 \pm 15$ & 9 & $59 \pm 12$ & $59 \pm 15$ \\
\hline $\begin{array}{l}\text { End systolic volume index } \\
\qquad\left(\mathrm{cm}^{3} / \mathrm{m}^{2}\right)\end{array}$ & & $18 \pm 6$ & 6 & $9 \pm 3 \ddagger$ & 10 & $9 \pm 4^{\prime \prime}$ & 9 & $8 \pm 2^{\prime \prime}$ & $9 \pm 3 \neq$ \\
\hline $\begin{array}{l}\text { Angiographic stroke index } \\
\left(\mathrm{cm}^{3} / \mathrm{m}^{2}\right)\end{array}$ & & $50 \pm 13$ & 6 & $62 \pm 15$ & 10 & $46 \pm 11$ & 9 & $51 \pm 12$ & $51 \pm 14$ \\
\hline Ejection fraction & & $0.73 \pm 0.07$ & 6 & $0.87 \pm 0.05^{\prime \prime}$ & 10 & $0.86 \pm 0.07^{\|}$ & 9 & $0.87 \pm 0.06^{\prime \prime}$ & $0.86 \pm 0.06^{\prime \prime}$ \\
\hline
\end{tabular}

$\mathrm{R}$, rest; $\mathrm{P}$, provocation; $n$, number of subjects; BSA, body surface area; BPM, beats per minute; peak $d p / d t$, peak rate of left ventricular pressure rise; NC, not calculated. $P$ values are derived using analysis of variance with Scheffè's test for multiple comparisons.

* Normal number of subjects for flow analysis were 29 at rest, 5 during provocation. Standard end-diastolic and end-systolic calculations were performed in all 29 normal subjects and $25 \mathrm{HCM}$ patients.

$\ddagger P<0.01$.

$\S P<0.05$.

" $P<0.001$.

sensor within the left ventricular outflow tract. The ascending aortic flow velocity wave form demonstrates a configuration that is markedly different from the control patient illustrated in Fig. 1. The majority of flow is confined to the early part of systole, with little or no forward flow present in late systole. The subsequent panels represent the pressure-flow relationships as the catheter is sequentially withdrawn. In panel B, the tip 

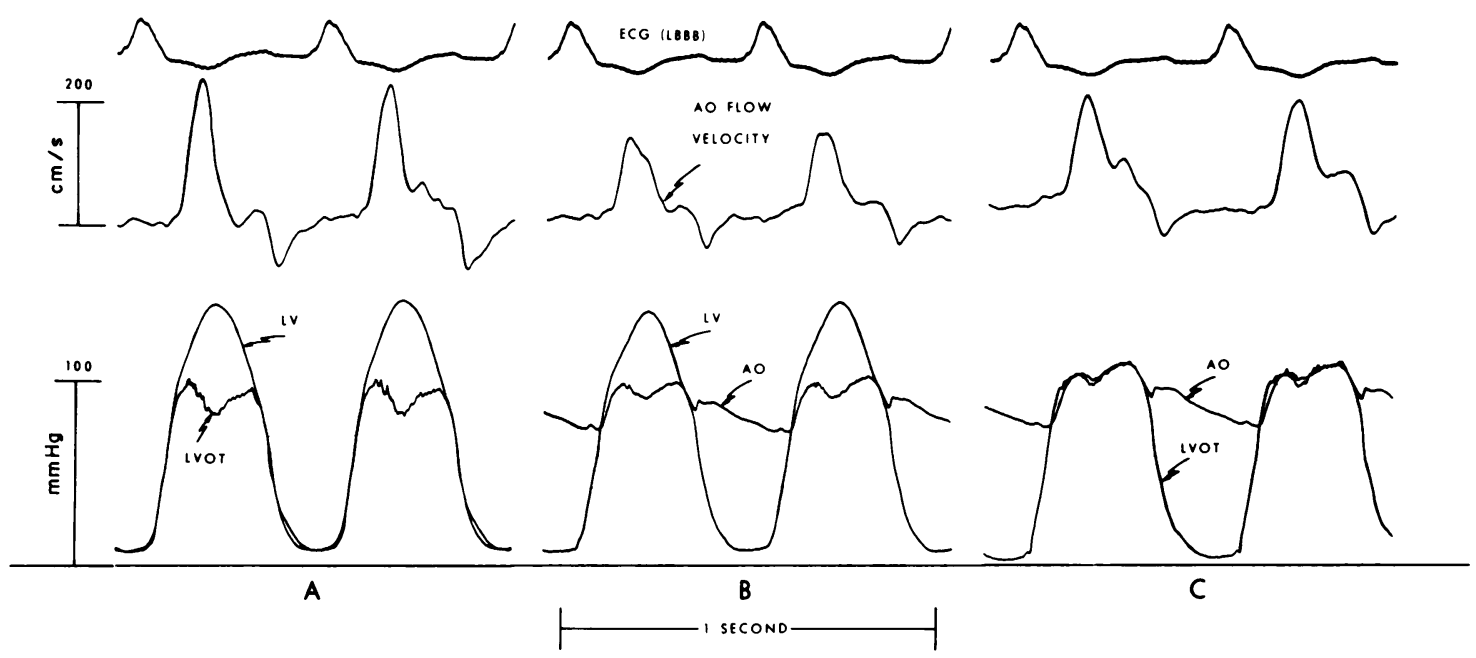

FIGURE 4 Left ventricular and aortic pressure-flow relationships in a patient from HCM group I. LV, left ventricle; LVOT, left ventricular outflow tract; AO, aorta. Panels A, B, and C illustrate these relationships as the multisensor catheter is sequentially withdrawn from deep within the left ventricle. The amplitude of the aortic velocity wave form is different in each of the three locations because of the nonuniform size of the proximal aorta. The aortic flow velocity wave forms at each location demonstrate a distinct abnormality with the majority of flow occurring in the first half of systole.

sensor remains within the apical portion of the left ventricle, with the second sensor in the ascending aorta just above the aortic valve. In panel $C$, the left ventricular outflow tract pressure and ascending aortic pressure are displayed. The configurations of the aortic flow velocity wave forms are similar in all three locations and demonstrate that the majority of ejection is confined to early systole.

HCM group II: intraventricular gradients with provocative maneuvers. In Fig. 5, the intraventricular and left ventricular aortic pressure-flow relationships are illustrated in a patient from group II during the resting state. There is a small physiologic flow-related gradient in early systole both within the ventricle and across the aortic valve as was demonstrated in the normal control patient in Fig. 1. However, no peak-topeak or pansystolic gradient is present. The ascending aortic flow velocity wave forms demonstrate that the majority of ejection is confined to early systole despite the absence of an "obstructive" intraventricular gradient. After isoproterenol infusion, abnormal gradients of 30-40 $\mathrm{mm} \mathrm{Hg}$ were easily generated.

HCM group III: no intraventricular gradients. In Fig. 6, the pressure-flow relationships from a patient in group III are illustrated. In the left panel, no abnormal intraventricular gradients are seen, either in the normal sinus beat or in the post-PVC beat. In the right panel, the relationships between the left ventricular and aortic pressures are demonstrated, and ejection in this patient also remains confined to the early part of systole. No abnormal gradients could be generated during iso- proterenol infusion in this patient or in any of the other patients subclassified into group III.

Using the computer techniques illustrated in Fig. 2, the percent $\mathrm{SV}$ as a function of the available systolic ejection period during rest is illustrated in the upper panel of Fig. 7. In the 22 control subjects in whom flow velocity measurements were made, ejection is completed $(100 \%$ SV) in $90 \pm 5 \%$ of the total available SEP. In all of the HCM patients, the total duration of flow into the aorta was significantly shorter than the available SEP. There were no differences among the subgroups, but significant differences were present between each of the subgroups and the normal control population. The distribution of left ventricular outflow into the earlier portions of systole in the HCM patients was unrelated to the presence or absence of an intraventricular pressure gradient.

The temporal distribution of ventricular outflow, as determined from the angiographic data in 22 of the control subjects and 24 of the HCM patients, is illustrated in the middle panel of Fig. 7. There is a striking similarity between the angiographic data and the aortic flow derived data, with all three subgroups demonstrating the ability to achieve minimal ventriculographic size in $\sim 63 \%$ of the available systolic ejection period. This is in contrast to the control group, where $\sim 86 \%$ of the ejection period is required to reach minimal systolic size.

The lower panel of Fig. 7 demonstrates similar results during provocative maneuvers, but because of the smaller sample sizes and the extremely conserva- 

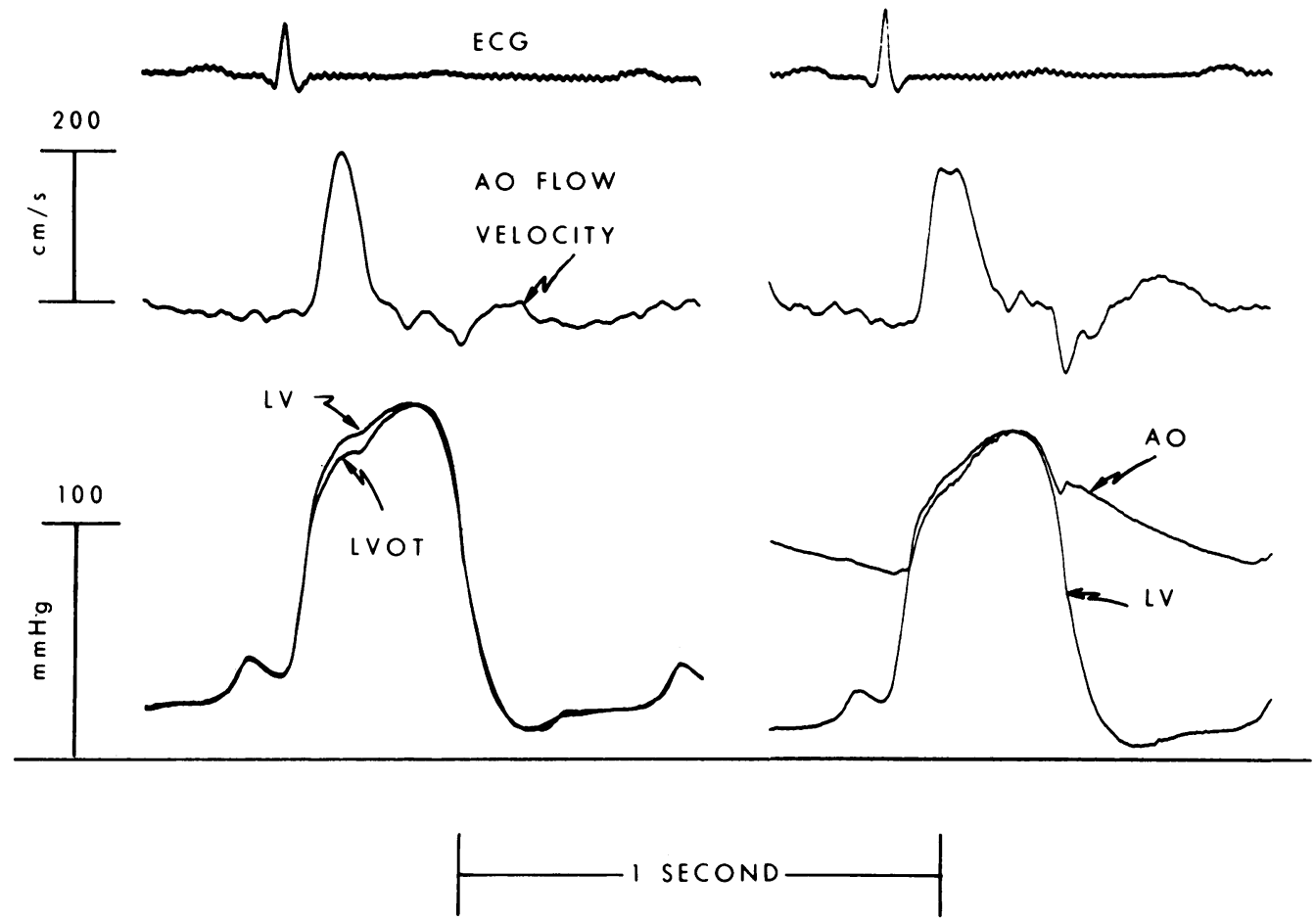

FIGURE 5 Left ventricular aortic pressure-flow relationships in a patient from HCM group II. Abbreviations are as in Fig. 3. Left panel illustrates pressures from the apical portion of the left ventricle (LV) and the left ventricular outflow tract (LVOT). Only a small physiologic flow-related gradient is present in early systole, but the aortic flow velocity signal is markedly abnormal, with ejection confined to early systole. Right panel illustrates the same relationships after the catheter has been withdrawn to the left ventricular aortic position.
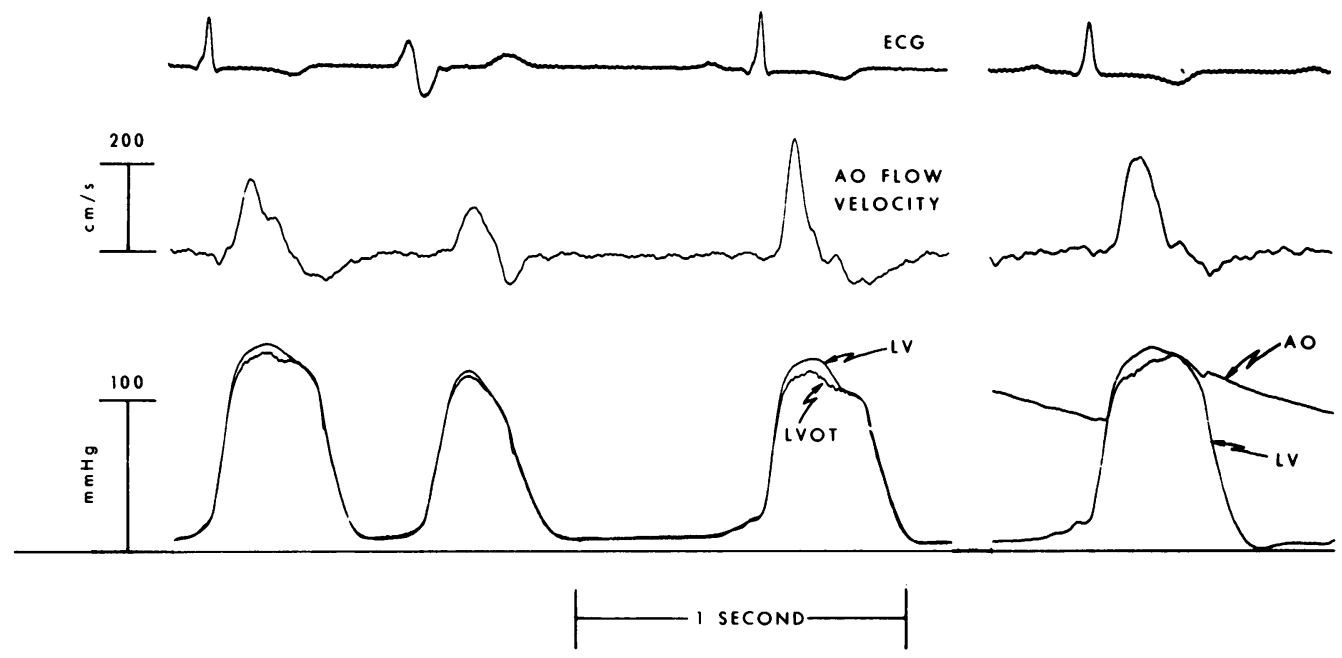

FigURE 6 Left ventricular aortic pressure-flow relationships in a patient from HCM group III. Abbreviations are as in Fig. 3. Left panel reveals pressures from the apical LV and LVOT. despite the presence of a premature ventricular contraction, no abnormal gradient is demonstrated in the post-PVC beat. In the left ventricular aortic position illustrated in the right panel, the same abnormalities of flow previously illustrated are also present in this patient despite the absence of an obstructive gradient. 
tive nature of the Scheffè examinations, only the differences in group II patients reached statistically significant levels.

The magnitude of aortic flow and related indices are summarized in Table IV. Peak flow indices during rest tended to be elevated in group I, and were significantly elevated in groups II and III when compared with the control population. These differences became less striking and did not reach statistical significance during inotropic stimuli. An indication of the differences in the shape of the ascending aortic flow wave form is found by calculating the ratio of peak flow to the mean systolic ejection rate (15). Significant differences between all HCM subgroups and the normal control population can be seen with peak flow rates usually exceeding three times the mean systolic ejection rate in HCM.

The available SEP, as determined from the ascending aorta pressure wave form, tends to be longer in HCM group I than the control group and HCM groups II and III, but this difference is not statistically significant. There is a significant prolongation of the SEP as determined by angiographic analysis, but the discrepancy between angiographic and pressure data is explained by the fact that angiographic SEP in four out of the six group I patients were derived from the sinus beats immediately following premature ventricular beats. The higher SEP values found in the two patients in group I during provocation were accompanied by much lower heart rates than the normal control group subjected to isoproterenol.

The forward flow time (FT)/SEP ratios (Table IV) numerically reflect the marked differences in ejection characteristics of all the HCM groups and correspond to the points at which 80,90 , and $100 \%$ of the $\mathrm{SV}$ is ejected, as displayed graphically in Fig. 7. On the average, $90 \%$ of the SV is ejected in all HCM groups in half of the available SEP. Since very small amounts of forward flow may exist for a considerable portion of late systole, the endpoints of the flow velocity wave forms and the angiographic volume curves may be misleading as indicators of the character of ejection. Whereas it appears that the forward flow time is significantly longer in group I than groups II and III when $100 \%$ of the $\mathrm{SV}$ is ejected, there are no significant differences among the three subgroups if this parameter is examined when $80 \%$ of the SV is ejected. The slightly longer flow time values determined angiographically may be explained by the measurement limitations imposed by the 16.7-ms sampling rate of the cineangiograms, slightly different heart rates during angiography, and the possible influence of a predominance of post-PVC beats in group $\mathrm{I}$.

Effects of mitral regurgitation. To determine whether or not mitral regurgitation is a significant contributing factor to the late systolic decrease in aortic flow, the HCM patients were divided into two groups

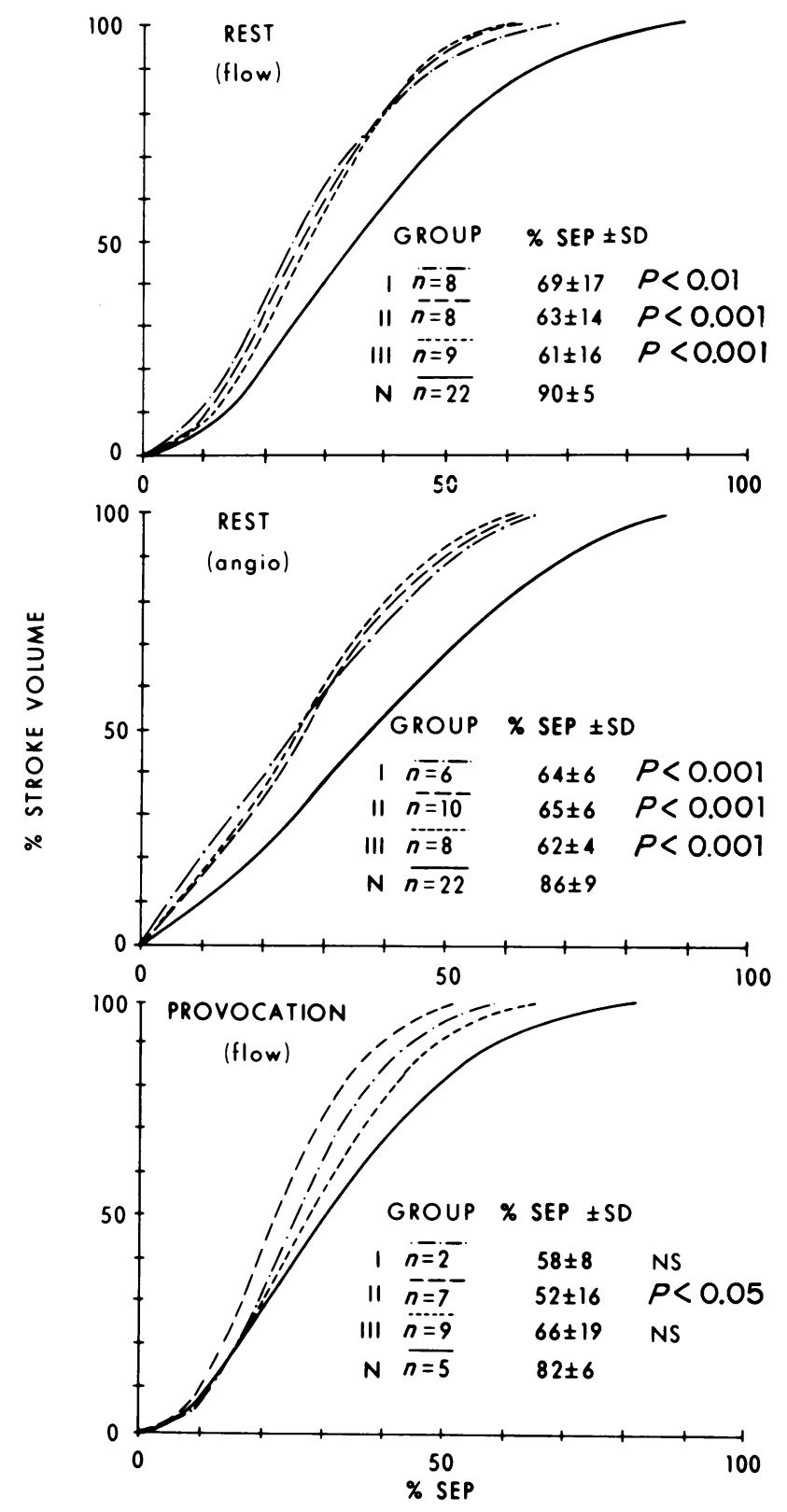

FIgURE 7 Temporal distribution of left ventricular outflow derived from aortic flow velocity wave forms during rest (upper panel) and provocation (lower panel). Similar data derived from frame-by-frame angiographic analysis during rest are illustrated in the middle panel. N, normal control population. The values shown in the lower right corner of each of the plots represent the percent SEP required for ejection of $100 \%$ of SV. These values correspond to the ratio FT/SEP for flow and angio data listed in Table IV. The statistical values represent comparison of the HCM subgroups vs. the normal control population for the end-points of the curves only. During rest, the characteristics of ejection are identical in all HCM subgroups, as demonstrated by both flow velocity and angiographic techniques. All HCM patients achieved completion of ejection between $60-70 \%$ of SEP as opposed to the normal control subjects who achieved the same end point in 85-90\% of SEP. Similar results are illustrated during provocative maneuvers. 
TABLE IV

Ejection Dynamics

\begin{tabular}{|c|c|c|c|c|c|c|c|c|c|}
\hline \multirow[b]{3}{*}{ Category } & & \multirow{3}{*}{$\frac{\text { Normal }^{*}}{\text { Mean } \pm \text { SD }}$} & \multicolumn{7}{|c|}{ Hypertrophic cardiomyopathy } \\
\hline & & & \multicolumn{2}{|r|}{ Group I } & \multicolumn{2}{|r|}{ Group II } & \multicolumn{2}{|r|}{ Group III } & \multirow{2}{*}{$\begin{array}{c}\text { All HCM } \\
\text { Mean } \pm \text { SD }\end{array}$} \\
\hline & & & $n$ & Mean \pm SD & $n$ & Mean \pm SD & $n$ & Mean \pm SD & \\
\hline Peak flow $\left(\mathrm{cm}^{3} / \mathrm{s}\right)$ & $\begin{array}{l}\mathbf{R} \\
\mathbf{P}\end{array}$ & $\begin{array}{r}704 \pm 125 \\
1,399 \pm 433\end{array}$ & $\begin{array}{l}8 \\
1\end{array}$ & $\begin{array}{c}811 \pm 119 \\
1,650\end{array}$ & $\begin{array}{l}8 \\
5\end{array}$ & $\begin{aligned} 980 & \pm 174 \ddagger \\
1,492 & \pm 377\end{aligned}$ & $\begin{array}{l}9 \\
5\end{array}$ & $\begin{array}{l}1,051 \pm 397 \S \\
1,764 \pm 372\end{array}$ & $\begin{array}{r}952 \pm 275 \ddagger \\
1,617 \pm 357\end{array}$ \\
\hline Peak flow index $\left(\mathrm{cm}^{3} / \mathrm{s} / \mathrm{m}^{2}\right)$ & $\begin{array}{l}\mathbf{R} \\
\mathbf{P}\end{array}$ & $\begin{array}{l}399 \pm 58 \\
677 \pm 176\end{array}$ & $\begin{array}{l}8 \\
1\end{array}$ & $\begin{array}{c}464 \pm 60 \\
727\end{array}$ & $\begin{array}{l}8 \\
5\end{array}$ & $\begin{array}{l}520 \pm 119 \S \\
789 \pm 150\end{array}$ & $\begin{array}{l}9 \\
5\end{array}$ & $\begin{array}{l}546 \pm 199 \S \\
875 \pm 170\end{array}$ & $\begin{array}{l}512 \pm 139 \S \\
817 \pm 150\end{array}$ \\
\hline $\begin{array}{l}\text { Mean systolic ejection rate } \\
\left(\mathrm{cm}^{3} / \mathrm{s}\right)\end{array}$ & $\begin{array}{l}\mathbf{R} \\
\mathbf{P}\end{array}$ & $\begin{array}{l}322 \pm 51 \\
551 \pm 96\end{array}$ & $\begin{array}{l}8 \\
1\end{array}$ & $\begin{array}{c}264 \pm 96 \\
553\end{array}$ & $\begin{array}{l}8 \\
5\end{array}$ & $\begin{array}{l}312 \pm 62 \\
385 \pm 159\end{array}$ & $\begin{array}{l}9 \\
5\end{array}$ & $\begin{array}{l}337 \pm 77 \\
579 \pm 192\end{array}$ & $\begin{array}{l}306 \pm 81 \\
479 \pm 183\end{array}$ \\
\hline $\begin{array}{l}\text { Peak flow/mean systolic } \\
\text { ejection rate }\end{array}$ & $\begin{array}{l}\mathbf{R} \\
\mathbf{P}\end{array}$ & $\begin{array}{l}2.2 \pm 0.3 \\
2.5 \pm 0.6\end{array}$ & $\begin{array}{l}8 \\
1\end{array}$ & $\begin{array}{l}3.3 \pm 0.7 \S \\
3.4\end{array}$ & $\begin{array}{l}8 \\
5\end{array}$ & $\begin{array}{l}3.2 \pm 1.0 \$ \\
4.5 \pm 2.6\end{array}$ & $\begin{array}{l}9 \\
5\end{array}$ & $\begin{array}{l}3.2 \pm 0.8 \S \\
3.5 \pm 1.2\end{array}$ & $\begin{array}{l}3.2 \pm 0.8 \S \\
3.9 \pm 1.8\end{array}$ \\
\hline $\operatorname{SEP}(m s)$ & $\begin{array}{l}R_{f} \\
R_{a} \\
P\end{array}$ & $\begin{array}{l}286 \pm 32 \\
278 \pm 36 \\
186 \pm 15\end{array}$ & $\begin{array}{l}8 \\
6 \\
2\end{array}$ & $\begin{array}{l}322 \pm 32 \\
356 \pm 53^{\prime \prime} \\
302 \pm 28^{\prime \prime}\end{array}$ & $\begin{array}{r}8 \\
10 \\
7\end{array}$ & $\begin{array}{l}284 \pm 26 \\
293 \pm 31 \\
228 \pm 29\end{array}$ & $\begin{array}{l}9 \\
8 \\
9\end{array}$ & $\begin{array}{l}292 \pm 28 \\
303 \pm 13 \\
232 \pm 31\end{array}$ & $\begin{array}{l}298 \pm 32 \\
313 \pm 42 \\
236 \pm 38\end{array}$ \\
\hline FT/SEP (80\% SV) & $\begin{array}{l}R_{f} \\
R_{a} \\
P\end{array}$ & $\begin{array}{l}54 \pm 5 \\
58 \pm 10 \\
49 \pm 6\end{array}$ & $\begin{array}{l}8 \\
6 \\
2\end{array}$ & $\begin{array}{l}40 \pm 8^{\prime \prime} \\
42 \pm 8 \S \\
38 \pm 6\end{array}$ & $\begin{array}{r}8 \\
10 \\
7\end{array}$ & $\begin{array}{l}39 \pm 8^{\prime \prime} \\
42 \pm 5^{\prime \prime} \\
33 \pm 9 \ddagger\end{array}$ & $\begin{array}{l}9 \\
8 \\
9\end{array}$ & $\begin{array}{l}40 \pm 9^{\prime \prime} \\
41 \pm 5^{\prime \prime} \\
41 \pm 10\end{array}$ & $\begin{array}{l}40 \pm 8^{\prime \prime} \\
42 \pm 5^{\prime \prime} \\
38 \pm 10\end{array}$ \\
\hline FT/SEP (90\% SV) & $\begin{array}{l}R_{f} \\
R_{a} \\
P\end{array}$ & $\begin{array}{l}65 \pm 6 \\
70 \pm 10 \\
57 \pm 6\end{array}$ & $\begin{array}{l}8 \\
6 \\
2\end{array}$ & $\begin{array}{l}48 \pm 10^{\prime \prime} \\
51 \pm 7^{\prime \prime} \\
44 \pm 8\end{array}$ & $\begin{array}{r}8 \\
10 \\
7\end{array}$ & $\begin{array}{l}47 \pm 10^{\prime \prime} \\
51 \pm 5^{\prime \prime} \\
40 \pm 11 \ddagger\end{array}$ & $\begin{array}{l}9 \\
8 \\
9\end{array}$ & $\begin{array}{l}46 \pm 11^{\prime \prime} \\
49 \pm 5^{\prime \prime} \\
48 \pm 13\end{array}$ & $\begin{array}{l}47 \pm 10^{\prime \prime} \\
50 \pm 5^{\prime \prime} \\
44 \pm 12\end{array}$ \\
\hline FT/SEP $(100 \%$ SV) & $\begin{array}{l}R_{f} \\
R_{a} \\
P\end{array}$ & $\begin{array}{l}90 \pm 5 \\
86 \pm 9 \\
82 \pm 6\end{array}$ & $\begin{array}{l}8 \\
6 \\
2\end{array}$ & $\begin{array}{l}69 \pm 17 \S \\
64 \pm 6^{\prime \prime} \\
58 \pm 8\end{array}$ & $\begin{array}{r}8 \\
10 \\
7\end{array}$ & $\begin{array}{l}63 \pm 14^{\prime \prime} \\
65 \pm 6^{\prime \prime} \\
52 \pm 16 \ddagger\end{array}$ & $\begin{array}{l}9 \\
8 \\
9\end{array}$ & $\begin{array}{l}61 \pm 16^{\prime \prime} \\
62 \pm 4^{\prime \prime} \\
66 \pm 19\end{array}$ & $\begin{array}{l}63 \pm 14^{\prime \prime} \\
64 \pm 5^{\prime \prime} \\
59 \pm 17\end{array}$ \\
\hline FT $(80 \%$ SV) & $\begin{array}{l}R_{f} \\
R_{a} \\
P\end{array}$ & $\begin{array}{r}158 \pm 22 \\
161 \pm 36 \\
91 \pm 10\end{array}$ & $\begin{array}{l}8 \\
6 \\
2\end{array}$ & $\begin{array}{l}125 \pm 20 \S \\
153 \pm 46 \\
115 \pm 12\end{array}$ & $\begin{array}{r}8 \\
10 \\
7\end{array}$ & $\begin{array}{c}111 \pm 26^{\prime \prime} \\
123 \pm 19 \ddagger \\
72 \pm 19\end{array}$ & $\begin{array}{l}9 \\
8 \\
9\end{array}$ & $\begin{array}{c}115 \pm 18 \\
125 \pm 18 \ddagger \\
98 \pm 24\end{array}$ & $\begin{array}{c}117 \pm 21^{\prime \prime} \\
131 \pm 30 \ddagger \\
89 \pm 25\end{array}$ \\
\hline FT $(90 \% \mathrm{SV})$ & $\begin{array}{l}R_{f} \\
R_{a} \\
P\end{array}$ & $\begin{array}{l}189 \pm 26 \\
194 \pm 36 \\
111 \pm 9\end{array}$ & $\begin{array}{l}8 \\
6 \\
2\end{array}$ & $\begin{array}{l}150 \pm 26 \\
181 \pm 46 \\
134 \pm 17\end{array}$ & $\begin{array}{r}8 \\
10 \\
7\end{array}$ & $\begin{array}{c}131 \pm 30^{\prime \prime} \\
149 \pm 20 \ddagger \\
87 \pm 25\end{array}$ & $\begin{array}{l}9 \\
8 \\
9\end{array}$ & $\begin{array}{l}132 \pm 21^{11} \\
148 \pm 19 \ddagger \\
113 \pm 30\end{array}$ & $\begin{array}{l}138 \pm 27^{\prime \prime} \\
157 \pm 31 \ddagger \\
105 \pm 30\end{array}$ \\
\hline FT $(100 \%$ SV) & $\begin{array}{l}R_{f} \\
R_{a} \\
P\end{array}$ & $\begin{array}{l}259 \pm 34 \\
239 \pm 39 \\
152 \pm 8\end{array}$ & $\begin{array}{l}8 \\
6 \\
2\end{array}$ & $\begin{array}{l}217 \pm 47 \\
230 \pm 47 \\
175 \pm 7\end{array}$ & $\begin{array}{r}8 \\
10 \\
7\end{array}$ & $\begin{array}{l}177 \pm 41^{\prime \prime} \\
189 \pm 24 \S \\
113 \pm 35\end{array}$ & $\begin{array}{l}9 \\
8 \\
9\end{array}$ & $\begin{array}{l}177 \pm 36^{\prime \prime} \\
187 \pm 20 \S \\
148 \pm 34\end{array}$ & $\begin{array}{l}190 \pm 44 \S \\
199 \pm 34 \ddagger \\
136 \pm 38\end{array}$ \\
\hline
\end{tabular}

$R_{f}$, rest data from flow; $R_{a}$, rest data from angio; P, provocation; FT, forward flow time from flow analysis or emptying time from angio analysis. $P$ values from Scheffè's test for multiple comparisons (38).

* Normal number of subjects: 22 at rest, 5 with isoproterenol.

$\ddagger P<0.05$.

$\S P<0.01$.

" $P<0.001$.

according to the presence or absence of mitral regurgitation. Fig. 8 summarizes the results displaying both flow and angiographic data for these two groups. If mitral regurgitation contributed significantly to the late systolic characteristics of aortic flow in the HCM patients, a continued angiographic ejection would be expected beyond cessation of ascending aortic flow as ventricular outflow was "redirected" into the left atrium. However, in the patients with mitral regurgita- tion, Fig. 8 reveals no significant disparity between the angiographic and flow velocity techniques. The patients without mitral regurgitation demonstrate the same characteristics with ejection completed in $60-63 \%$ of the SEP. A careful analysis of individual patient data also revealed that the slightly longer absolute values of angiographically determined flow times, compared with the same parameter determined from the flow velocity data (Table III), did not correlate 

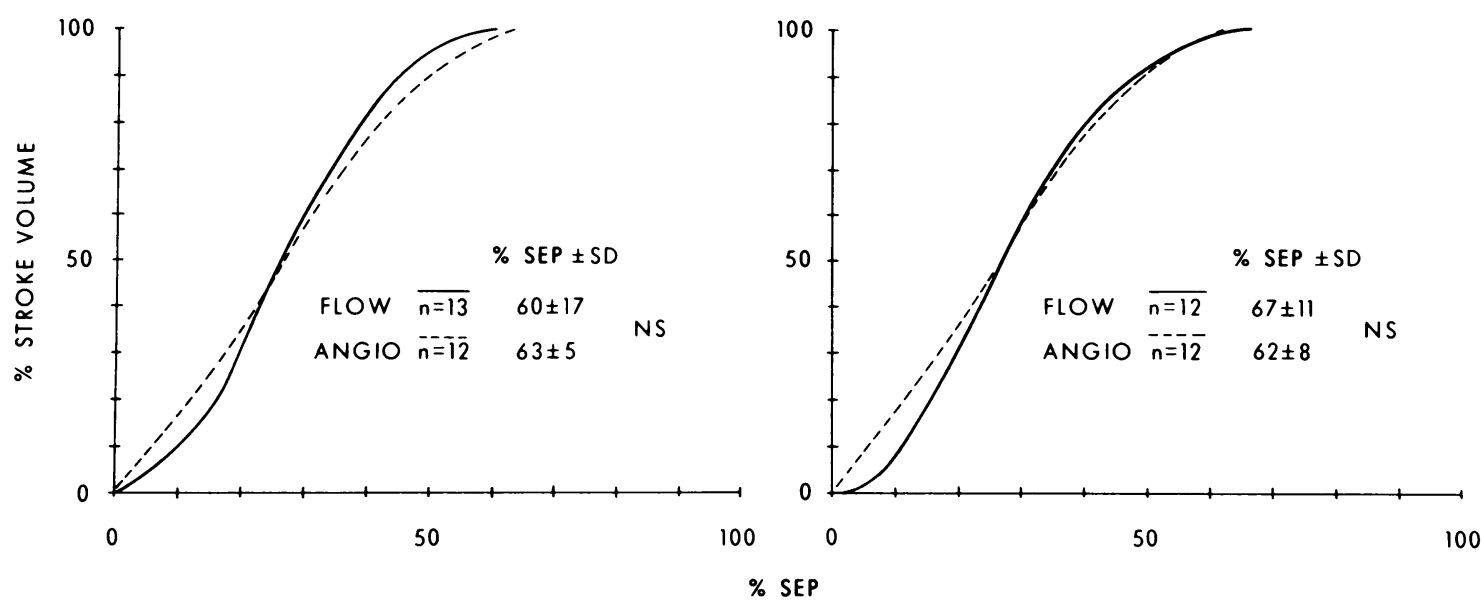

FIgURE 8 Temporal distribution of left ventricular outflow from both flow velocity and angiographic techniques analyzed in HCM patients without mitral regurgitation (left panel) and those with mitral regurgitation (right panel). NS, no significant difference between the flow and angiographic techniques. If mitral regurgitation were responsible for the decreased aortic flow in mid to late systole, a disparity between angiographic emptying and aortic flow would be predicted. The right panel illustrates no significant difference between these two techniques.

to the presence or absence of mitral regurgitation. These results indicate that these ejection characteristics are not dependent upon the presence of an "escape route" into the left atrium.

\section{DISCUSSION}

Although there is little published information regarding the flow characteristics of patients with hypertrophic cardiomyopathy in the absence of intraventricular pressure gradients, several investigators have measured or derived instantaneous arterial flow in patients with intraventricular gradients (15, 16, 40-43). Hernandez et al. (16), using the pressure gradient technique (44), studied ascending aortic flow in four patients with HCM and resting intraventricular gradients at the time of catheterization. These investigators found results similar to ours by demonstrating that $80 \%$ of the stroke output occurred during the first half of systole as compared with $57 \%$ in five control subjects. They also noted that the marked decrease in forward flow during the latter half of systole was found only in patients with HCM. In discussing the possible mechanisms responsible for the decrease in late systolic flow, these investigators mentioned the possibility that an abnormally powerful and rapid contraction of the left ventricle could produce almost total ejection early in systole, so that in late systole the ventricle was virtually empty. Not long after this report, Pierce et al. (15) measured ascending aortic blood flow using an external electromagnetic flow probe placed around the aortae of four patients about to undergo ventricular myotomy and recorded flow wave forms very similar to those derived by Hernandez and demonstrated in our study. They concluded that the decrease in late systolic flow was secondary to a mechanical obstruction, the severity of which could be modified by various interventions.

Several other investigators (40-43) have studied peripheral arterial wave forms or aortic arch flow using transcutaneous doppler techniques in patients with HCM. These studies are fraught with several problems either related to technique, a lack of knowledge regarding the spatial flow velocity profile at the measuring site, and/or an interpretation of central hemodynamics based on peripheral arterial wave forms. The pressure and flow wave forms in the systemic circulation are primarily determined by properties of the peripheral vascular system with wave reflections playing a major role in man $(26,45,46)$. These problems were avoided in our study by measuring the instantaneous pressure-flow relationships in the ascending aorta.

In using flow velocity wave forms to represent instantaneous volumetric flow, the ascending aortic flow velocity profile was assumed to be blunt. Although this assumption may be valid for patients with normal ejection dynamics, there are no data available regarding the velocity profile in patients with HCM. Several observations suggest that the flow velocity wave forms in HCM do represent volumetric flow. First, the signals obtained by Pierce et al. (15) using an external cuff flowmeter are very similar to those obtained by the velocity probe in this study. Second, no jet effect 
could be seen angiographically in our patients, and the propagation of contrast media into the aorta during ventriculography demonstrated a relatively blunt profile. However, to test the validity of these assumptions and to add an independent method, the dynamics of ventricular outflow were additionally analyzed with frame-by-frame angiographic analysis. The results using this method were identical to those obtained from the flow-velocity probe and reveal that early and rapid emptying of the left ventricle is responsible for the flow patterns obtained in the aortic root.

To evaluate the duration of forward flow as a function of the total duration of systole and to avoid the effects of different heart rates on systolic pressure and flow time intervals (SEP and flow time), we chose to analyze the temporal distribution of ejection in terms of percent SEP. Interpreting our data in this manner, it appears that all patients with HCM are significantly different from normal and have extraordinarily hyperdynamic ventricles, which result in increased rates of ejection with abbreviated emptying times and flow periods. The marked similarities in ejection characteristics between the three HCM subgroups would suggest that the presence of an intraventricular gradient does not necessarily imply a coexistent impediment to ventricular emptying. To conclude that this is a valid interpretation of these data depends upon whether or not normalization of time intervals masks true differences between the HCM subgroups.

In analyzing absolute data instead of percentages, the SEP determined from aortic pressure is greater in patients from HCM group I when compared with normals and those in groups II and III (Table IV). However, these differences are not statistically significant. If the total available SEP is indeed prolonged in patients with intraventricular gradients, a key question is whether such a prolongation is due to an impediment to outflow or to other factors that affect the duration of mechanical systole, such as delayed relaxation (47). The observation in the "nonobstructed" patients that the actual duration of forward flow is significantly shorter than the available SEP implies that the total duration of systole may be dependent on electrical/mechanical factors other than flow alone. To avoid analyzing the dynamics of outflow from data derived from pressure signals, this study investigated the effects of obstruction on ejection by actually measuring the physiologic parameter that is supposedly obstructed, i.e., flow. The first conclusion is that qualitative abnormalities of the flow wave form, which were previously attributed to obstruction (15), are also present in patients without obstruction.

When the absolute duration of forward flow was examined (from flow velocity or angiographic measurements), it appears that HCM group I patients have a longer duration of forward flow than groups II and III during rest and values not significantly different from the control group. One possible explanation for these differences could be based on a hypothesis that all patients with HCM have hypertrophied and hyperdynamic ejection characteristics, but in one group (perhaps because of differences in the distribution of hypertrophy and the geometry of the papillary muscles, mitral valve, and septum), high ejection rates result in Bernoulli effects on the mitral valve, causing it to move into the outflow tract and produce obstruction. In turn, a relative prolongation of ventricular emptying and flow times occurs in these patients when compared with the nonobstructed patients with HCM. However, using the endpoints of the flow signal ( $100 \%$ forward flow time) or the angiographic emptying curve (100\% emptying time) to judge the character of ejection may be quite misleading, since very small values of forward flow may exist for a considerable portion of late systole. To avoid this problem, the time required for ejection of $80 \%$ of the SV was also examined. During rest, when average heart rates were similar, all HCM groups revealed shorter time intervals than the control group with no significant differences among subgroups. Thus, normalization to percent SEP did not mask differences between the subgroups and allowed for an evaluation of the inotropically stimulated states where heart rates varied considerably among groups.

The possibility that the abnormal flow wave forms in patients with HCM are due to redirection of flow from the aorta to the left atrium through functional mitral regurgitation (48) was also addressed in this study by carefully examining the temporal sequence of ventriculographic emptying in relationship to aortic flow. Although there was a higher incidence of mitral regurgitation in those patients who demonstrated resting intraventricular pressure gradients, a detailed analysis of the timing of ejection in these patients did not support an eject-obstruct-regurgitate mechanism. Virtually complete, early, and rapid emptying of the left ventricle is a characteristic shared by all $\mathrm{HCM}$ patients in this study.

These conclusions may explain why a common symptom complex $(7,13,39,49)$ is seen in both the obstructive and nonobstructive forms of this disease, and suggest that hypertrophy and abnormal ventricular compliance play the dominant role in HCM. The symptomatic improvement that follows surgical procedures (50) to relieve obstruction may be secondary to an alteration of any number of factors that could result in changes of systolic and diastolic function. Systematic studies of pre- and postoperative left ventricular performance, including the dynamics of left ventricular outflow and the mechanical properties of the left ventricle, are necessary to bring an increased understanding of the pathophysiology of HCM and the role of surgery in this fascinating disease. 


\section{ACKNOWLEDGMENTS}

The authors are indebted for the invaluable assistance and talents of Mr. Thomas Dunne and the technicians of the Cardiac Catheterization Laboratory at Brooke Army Medical Center. CPT J. P. Giolma, Ph.D., SP5 Thomas R. Deojay, and Mr. Jim Bagwell provided outstanding assistance in data processing and statistical analysis. This study would not have been possible without the cooperation of the physicians of the Cardiology Service. Thanks to Bettye Jo Hairston and Helen Smith for their untiring and outstanding help in typing and editing this manuscript. The photography and graphics were provided by Mr. Earl Ferris, SP5 David Lovelace, SP5 Georgette Toshok, and Mr. Douglas Meyer.

\section{REFERENCES}

1. Brock, R. C. 1959. Functional obstruction of the left ventricle (acquired aortic subvalvular stenosis). Guy's Hosp. Rep. 106: 221-239.

2. Criley, J. M., K. B. Lewis, R. I. White, Jr., and R. S. Ross. 1965. Pressure gradients without obstruction. A new concept of "hypertrophic subaortic stenosis." Circulation. 32: 881-887.

3. Goodwin, J. F. 1970. Congestive and hypertrophic cardiomyopathies. A decade of study. Lancet. I: 731-739.

4. Braunwald, E., A. G. Morrow, W. P. Cornell, M. M. Aygen, and T. F. Hilbish. 1960. Idiopathic hypertrophic subaortic stenosis: clinical, hemodynamic and angiographic manifestations. Am. J. Med. 29: 924-935.

5. Wigle, E. D., P. Auger, and Y. Marquis. 1966. Muscular subaortic stenosis. The initial left ventricular inflow tract pressure as evidence of outflow tract obstruction. Can. Med. Assoc. J. 95: 793-797.

6. Ross, J., Jr., E. Braunwald, J. H. Gault, D. T. Mason, and A. G. Morrow. 1966. The mechanism of the intraventricular pressure gradient in idiopathic hypertrophic subaortic stenosis. Circulation. 34: 558-578.

7. Frank, S., and E. Braunwald. 1968. Idiopathic hypertrophic subaortic stenosis. Clinical analysis of 126 patients with emphasis on the natural history. Circulation. 37: 759-788.

8. Shah, P. M., C. E. Gramiak, and D. H. Kramer. 1969. Ultrasound localization of left ventricular outflow obstruction in hypertrophic obstructive cardiomyopathy. Circulation. 40: 3-11.

9. Adelman, A. G., E. D. Wigle, N. Ranganathan, G. D. Webb, B. S. L. Kidd, W. G. Bigelow, and M. D. Silver. 1972. The clinical course in muscular subaortic stenosis. A retrospective and prospective study of 60 hemodynamically proven cases. Ann. Intern. Med. 77: 515525.

10. Shah, P. M., A. G. Adelman, E. D. Wigle, F. L. Gobel, H. B. Burchell, T. Hardarson, R. Curiel, C. de la Calzada, C. M. Oakley, and J. F. Goodwin. 1974. The natural (and unnatural) history of hypertrophic obstructive cardiomyopathy. Circ. Res. 34, 35 (Suppl. 2): 179-195.

11. Henry, W. L., C. E. Clark, J. M. Griffith, and S. E Epstein. 1975. Mechanism of left ventricular outflow obstruction in patients with obstructive asymmetric septal hypertrophy (idiopathic hypertrophic subaortic stenosis). Am. J. Cardiol. 35: 337-345.

12. Criley, J. M., P. A. Lennon, A. S. Abbasi, and A. H. Blaufuss. 1976. Hypertrophic cardiomyopathy. In Clinical Cardiovascular Physiology. Herbert J. Levine, editor. Grune \& Stratton, New York. 771-828.

13. Braunwald, E., C. T. Lambrew, S. D. Rockoff, and A. G.
Morrow. 1964. Idiopathic hypertrophic subaortic stenosis I. Circulation. 30 (Suppl. 4): 3-119.

14. Wilson, W., J. M. Criley, and R. S. Ross. 1967. Dynamics of left ventricular emptying in hypertrophic subaortic stenosis. A cineangiographic and hemodynamic study. Am. Heart J. 73: 4-16.

15. Pierce, G. E., A. G. Morrow, and E. Braunwald. 1964. Idiopathic hypertrophic subaortic stenosis III. Circulation. 30 (Suppl. 4): 152-174.

16. Hernandez, R. R., J. C. Greenfield, Jr., and B. W. McCall. 1964. Pressure-flow studies in hypertrophic subaortic stenosis. J. Clin. Invest. 43: 401

17. Henry, W. L., C. E. Clark, and S. E. Epstein. 1976. Asymmetric septal hypertrophy. Echocardiographic identification of the pathognomenic anatomic abnormality of IHSS. Circulation. 47: 225-233.

18. Simon, A. L., J. Ross, Jr., and J. H. Gault. 1967. Angiographic anatomy of the left ventricle and mitral valve in idiopathic hypertrophic subaortic stenosis. Circulation. 36: 852-867.

19. Murgo, J. P., and H. D. Millar. 1972. A new cardiac catheter for high fidelity differential recordings. In 25th Annual Conference on Engineering in Medicine and Biology. Bal Harbour, Fla. 303.

20. Millar, H. D., L. E. Baker. 1973. A stable ultraminiature catheter-tip pressure transducer. Med. Biol. Eng. 11: 86-89.

21. Murgo, J. P. 1975. New techniques in cardiac catheterization: the advantages of multisensor catheters. In Proceedings of the International Conference on Biomedical Transducers. Paris, France. 41-46.

22. Murgo, J. P. 1975. Multisensor cardiac catheterization. New methods to study cardiovascular dynamics in man. In Proceedings of the 28th Annual Conference on Engineering in Medicine and Biology. New Orleans, La. 503. (Abstr.)

23. Murgo, J. P., S. A. Altobelli, J. F. Dorethy, J. R. Logsdon, and G. M. McGranahan. 1975. Normal ventricular ejection dynamics in man during rest and exercise. Am. Heart Assoc. Monogr. 46: 92-101.

24. Murgo, J. P., J. P. Giolma, and S. A. Altobelli. 1977. Signal acquisition and processing for human hemodynamic research. In Proceedings of the Institute of Electrical \& Electronics Engineers. 65: 696-702.

25. Nichols, W. W., C. J. Pepine, C. R. Conti, L. G. Christie, and R. L. Feldman. 1980. Evaluation of a new cathetermounted electromagnetic velocity sensor during cardiac catheterization. Catheterization Cardiovasc. Diagn. 6: $97-113$.

26. Murgo, J. P., N. Westerhof, J. P. Giolma, and S. A. Altobelli. 1980. Aortic input impedance in normal man: relationship to pressure wave forms. Circulation. 62: 105-116.

27. Kasser, I. S., and J. W. Kennedy. 1969. Measurement of left ventricular volumes in man by single-plane cineangiography. Invest. Radiol. 4: 83.

28. Ling, S. C., H. B. Atabek, D. L. Fry, D. J. Patel, and J. S. Janicki. 1968. Application of heated-film velocity and shear probes to hemodynamic studies. Circ. Res. 23: 789-80.

29. Schultz, D. L. 1972. Pressure and flow in large arteries. 1972. In Cardiovascular Fluid Dynamics. D. H. Bergel, editor. Academic Press, Inc., New York. Vol. 1. 287-314.

30. Seed, W. A., and N. B. Wood. 1971. Velocity patterns in the aorta. Cardiovasc. Res. 5: 318-330.

31. Uther, J. B., K. L. Peterson, R. Shabetai, and E. Braunwald. 1973. Measurement of ascending aortic flow patterns in man. J. Appl. Physiol. 34: 513-518. 
32. Mason, D. T., I. T. Gabe, J. H. Gault, J. Ross, Jr., E. Braunwald, and J. P. Shillingford. 1970. Applications of the catheter-tip electromagnetic velocity probe in the study of the central circulation in man. Am. J. Med. 49: 465-470.

33. Warbasse, J. R., B. H. Hellman, R. E. Gillilan, R. R. Hawley, and H. I. Babitt. 1969. Physiologic evaluation of a catheter tip electromagnetic velocity probe. Am. J. Cardiol. 23: 424-433.

34. Gabe, I. T., J. H. Gault, J. Ross, Jr., D. T. Mason, C. J. Mills, J. P. Shillingford, and E. Braunwald. 1969. Measurement of instantaneous blood flow velocity and pressure in conscious man with a catheter-tip velocity probe. Circulation. 40: 603-614.

35. Bond, R. F., and C. A. Barefoot. 1967. Evaluation of a electromagnetic catheter tip velocity-sensitive blood flow probe. J. Appl. Physiol. 23: 403-409.

36. Mills, C. J., and J. P. Shillingford. 1967. A catheter tip electromagnetic velocity probe and its evaluation. Cardiovasc. Res. 1: 263-273.

37. Giolma, J. P. 1975. Cardiac related parameters of thoracic electrical impedance. Ph.D. thesis, Carnegie Mellon University, Pittsburgh.

38. Scheffé, H. 1953. A method of judging all contrasts in the analysis of variance. Biometrika. 40: 87.

39. Epstein, S. E., W. L. Henry, C. E. Clark, W. C. Roberts, B. J. Maron, V. J. Ferrans, D. R. Redwood, and A. G. Marrow. 1974. Asymmetric septal hypertrophy. Ann. Intern. Med. 81: $650-680$.

40. Joyner, C. R., Jr., F. S. Harrison, and J. W. Gruber. 1971. Diagnosis of hypertrophic subaortic stenosis with a doppler velocity flow detector. Ann. Intern. Med. 74: $692-696$.

41. Boughner, D. R., D. R. Schuld, and J. A. Persaud. 1975. Hypertrophic obstructive cardiomyopathy. Assessment by echocardiographic and doppler ultrasound techniques. Br. Heart J. 37: 917-923.
42. Kinoshita, N., Y. Nimura, K. Miyatake, S. Nagata, H. Sakakibara, T. Hayaski, M. Asao, Y. Terao, and H. Matsuo. 1978. Studies on flow patterns in the aortic arch in cases with hypertrophic cardiomyopathy using pulsed ultrasonic doppler technique. J. Cardiogr. (Japan). 8: 235-332.

43. Gault, J. H., R. Ross, Jr., and D. T. Mason. 1966. Patterns of brachial arterial blood flow in conscious human subjects with and without cardiac dysfunction. Circulation. 34: 833-848.

44. Fry, D. L. 1959. The measurement of pulsatile blood flow by the computed pressure gradient technique. Institute of Radio Engineers, Transactions on Medical Electronics. ME-6, 259: 264.

45. Mills, C. J., I. T. Gabe, J. H. Gault, D. T. Mason, J. Ross, Jr., E. Braunwald, and J. P. Shillingford. 1970. Pressure flow relationships and vascular impedance in man. Cardiovasc. Res. 4: 405-417.

46. Murgo, J. P., J. P. Giolma, and N. Westerhof. 1979. Manipulation of aortic pressure and flow wave reflections with the Valsalva maneuver. Circulation. 58(2): 76. (Abstr.)

47. Sanderson, J. E., D. G. Gibson, D. J. Brown, and J. F. Goodwin. 1977. Left ventricular filling in hypertrophic cardiomyopathy. An angiographic study. Br. Heart J. 39: $661-670$.

48. Wigle, E. D., A. G. Adelman, P. A. Anger, and Y. Marquis. 1969. Mitral regurgitation in muscular subaortic stenosis. Am. J. Cardiol. 24: 698-706.

49. Maron, B. J., W. C. Roberts, J. E. Edwards, H. A. McAllister, D. D. Foley, and S. E. Epstein. 1978. Sudden death in patients with hypertrophic cardiomyopathy: characterization of 26 patients without functional limitation. Am. J. Cardiol. 41: 803-810.

50. Maron, B. J., W. H. Merrill, P. A. Freier, K. M. Kent, S. E. Epstein, and A. G. Morrow. 1978. Long-term clinical course and symptomatic status of patients after operation for hypertrophic subaortic stenosis. Circulation. 57: 1205-1213. 